\title{
SUSTAINABLE DESIGN ON PACKAGING: A CASE STUDY IN A CHINESE TOWN
}

\author{
Xiong, Xue; \\ Zhang, Xiaotong \\ Tongji Uiversity
}

\begin{abstract}
Packaging waste has become a significant problem in China. The paper stems from growing awareness of packaging and environmental protection. To explore the perception of Chinese consumers on packaging and sustainability, the research takes Wuzhen as a case, based on the economic situation, industrial advantages and potential for implementing sustainable measures. It also investigates the current situation of packaging design in the town. By using empirical analysis in the form of questionnaire and semi-structured interview, the survey was carried out from three aspects: tourist attitude towards shopping products in Wuzhen, tourist perceptions of packaging characteristics, tourist perceived importance of sustainable. In the end, the paper discusses the packaging design of Wuzhen from the perspective of materials, function and design. This research is aimed to explore Chinese consumers' views of packaging and environmental sustainability and provide insights to the packaging industry to further enhance the effectiveness of environmentally packaging.
\end{abstract}

Keywords: Sustainability, Case study, Packaging, Industrial design

Contact:

Xiong, Xue

Tongji Uiversity

College of Design and Innovation

China, People's Republic of

814542137@qq.com 


\section{INTRODUCTION}

Human activities produce garbage, whereas too much garbage can cause great harm to the environment. In recent years, garbage pollution has become a great concern to Chinese society. According to relevant statistics, the average annual growth rate of garbage in the world is $8.42 \%$, while the rate in China has exceeded $10 \%$. The accumulative amount of municipal solid waste in China has reached 7 billion tons. At present, 2 / 3 of the large and medium-sized Chinese cities are surrounded by garbage, and $1 / 4$ of the cities have no suitable places to stack garbage.

In order to promote sustainable development, China launched a new MSW (municipal solid waste) classification strategy in 2017 (Zhou et al. 2019). On July 11, 2019, Shanghai became the first city in China to implement compulsory classification of domestic waste. Four categories of domestic waste classification standards were defined, namely recyclable, hazardous, wet and dry waste. Citizens are required to classify garbage and put different garbage into designated dustbin. Chinese people's attitude towards sustainability are increasingly serious and actively cooperate with the authorities in the implementation of the policy.

What is more, hotels and restaurants are no longer allowed to provide disposable articles to customers. By 2020, 46 major cities have announced the implementation plan of waste classification, which demands city residents to put rubbish classification into practice.

Packaging industry is one of the businesses that produces the most "waste" since packaging products are closely related to everyday life. They are not only large in quantity, but also generally disposable. The amount of waste generated by packaging is huge, which accounts for a high proportion in domestic waste. Therefore, packaging design based on the concept of sustainable development has become an important research direction.

The research stems from growing interest in packaging and environmental protection. The purpose of it is to explore Chinese consumers' views of packaging and environmental sustainability, and to investigate the current situation of packaging design, which could contribute to the study of environmental sustainability development.

\section{SUSTAINABLE PACKAGING DESIGN}

\subsection{Sustainable Packaging Design}

In the book entitled Design for the Real World, Papanek and Fuller state that Industrial designers, industries and administrations should all together give an answer to the question of how much social and ecological harm is done to our society (Papanek 1971). Sustainable designed packaging can be defined as a design that evokes explicitly or implicitly the environmentally-friendly of the packaging via its structure (Magnier and Crie 2015). Sustainable design may also be defined as environmentally responsible product design and development, which incorporates a product life-cycle perspective together with approaches integrating work, culture and organizational skills (Kim 2008).

In manufacturing, the raw material is converted into useful products through a series of value and nonvalue added processes, each of which consumes resources in terms of material, energy, time and human efforts (Thanki and Thakkar 2016). Sustainable development requires that design should reduce unnecessary cost of goods and packaging waste to the environment throughout the life cycle from production to sales, which strives to keep the goods in line with the harmonious and sustainable development of human, society and nature. Packaging is not merely a box, but it is a system that enables the storage, handling and transportation become safe, cost-effective and efficient. Sustainable packaging, hence, should be both efficient, aiming at minimizing materials, energy and resources depletion, and effective, i.e. it should maximize its positive role of protection towards food. Overall, the "packaging" environmental issue should not be generalized, and it would be more appropriate to focus on the "packaging-product system" instead on packaging alone (Licciardello 2017).

In order to meet this requirement, designers should constantly innovate and practice to make all factors balance in dynamic development, so as to improve production efficiency, reduce resource consumption, eliminate environmental pollution and realize sustainable development of design. Some experts analysed existing sustainable packaging design tools and found that plenty of tools have limitations in demonstrating usage and balancing trade-off situations. Beitzen-Heineke, Balta-Ozkan and Reefke (2017) conducted a research on zero-packaging and interviewed with shops which have stopped using of disposable plastic packaging for their entire product range. Sustainable production 
design and methods are important contributors to the solution of environmental problems such as waste reduction and natural resource conservation, reducing production costs and thus reducing product prices and operating profits (Özgen 2017).

Some papers discussed sustainable packaging from consumers response. The behavioural discrepancy was examined between consumers with high environmental concern and low concern (Bamberg 2003). Additionally, consumer emotions are critical factors influencing environmental purchase decisions and both positive and negative emotions showed great effect on purchase intention (KoenigLewis et al. 2014). Magnier and Schoormans (2015) found that consumers' level of environmental concern influenced their responses to different packages. Hoegg and Alba (2011) investigated how judgements were affected by production form. Nordin and Selke suggested (2010) continuous feedback is the key to improve the effectiveness of sustainable products because most consumers were found to have little knowledge of sustainable packaging.

\subsection{Chinese Packaging Industry}

With the rapid development of China's packaging industry, packaging production plays an increasingly important role in promoting national economic construction and improving people's material and cultural life. Especially in recent years, the vigorous development of China's e-commerce industry accelerates the prosperity of Internet and its accompanying business-express service (Huabo et al. 2019). The service brings various packaging materials into our life. Food delivery service also results in significant environmental concerns for the waste packaging (Liu et al. 2020; Song et al. 2018). The total amount of packaging waste generated by food delivery in China increased from 0.2 million metric tons (Mt) in 2015 to $1.5 \mathrm{Mt}$ in 2017, which only makes up about $1 \%$ of the annual urban waste in China (Song et al. 2018).

As an independent industry system, the development of packaging industry has been included in the national economic and social development plan. In 2019, there were 7916 enterprises above designated size in packaging industry, 86 more than in 2018 (Figure 1). The total profit of China's packaging industry above designated size was 52.68 billion yuan. That cause the quantity of packages in China constantly grow (Hao et al. 2019).

In terms of materials, the packaging industry can be divided into four categories: paper packaging, plastic packaging (including plastic film), metal packaging and glass packaging, among which paper packaging has always occupied a leading position in the industry. With the control of plastic bags in recent years, environmental sustainability has become an important target for the industry. Sustainable packaging is the product of social development and an inevitable trend in the future. The popularization of sustainable concept can alleviate the contradiction between human and natural environment.

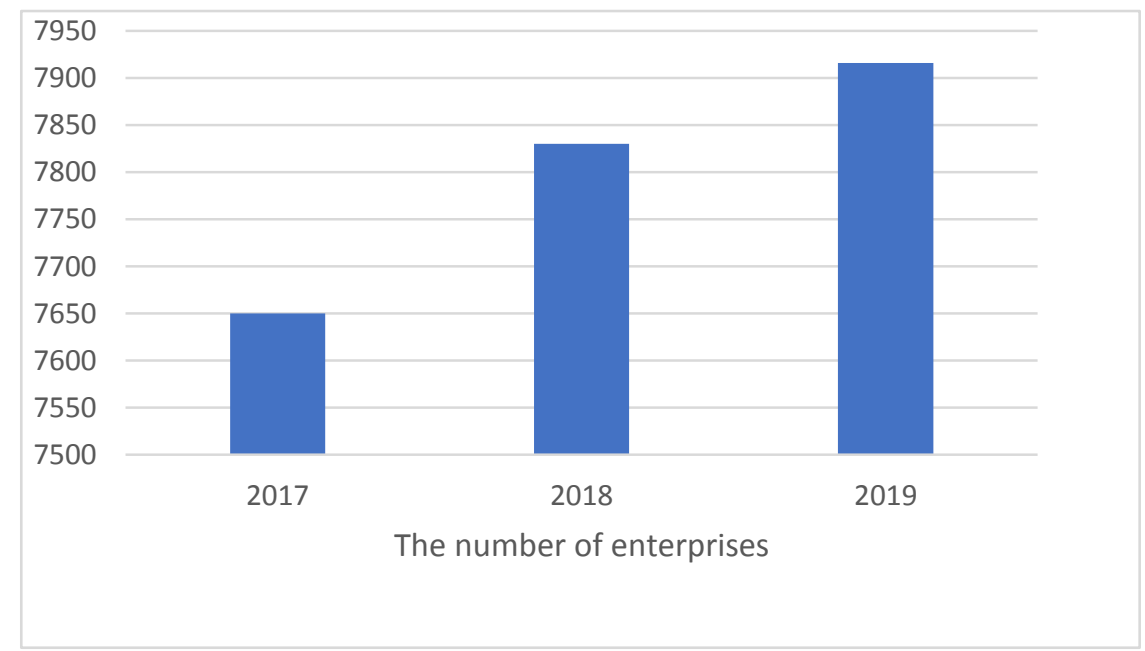

Figure 1. 2017-2019 The number of enterprises above designated size in China's packaging industry 


\section{METHODS AND CASE DESCRIPTIONS}

This paper takes Wuzhen as a case study. It was selected based on the following factors: economic situation, industrial advantages and potential for implementing sustainable measures. Wuzhen is a typical ancient town with a history of 1300 years in southern China, which has been included in the preliminary list of world cultural heritage. The town has geographical advantage, about 80 kilometers (50miles) from both Hangzhou and Suzhou, and approximately 140 kilometers from Shanghai. Wuzhen is an international tourist destination for sightseeing, leisure vacation and business meetings. The scenic area received 8.179 million tourists throughout the year, most from Shanghai, Zhejiang or Jiangsu province, therefore the local specialties have a good market in high season. The statistics of table 1 were collected in 2019 from Tongxiang Municipal People's Government (http://www.tx.gov.cn/).

Table 1. Key characteristics of the case town.

\begin{tabular}{|l|r|}
\hline Population & 86746 \\
\hline Size in square km & 71.79 \\
\hline Location & Southeast China \\
\hline GDP & 6.830 billion yuan \\
\hline Industrial advantages & the tertiary industry \\
\hline Tourist reception & 8.179 million \\
\hline
\end{tabular}

The research data on this paper was collected from the tourists in the two different time periods: 3rd5th August 2020 and 8th-9th March 2021. It was conducted in a Chinese town Wuzhen through an onthe-spot questionnaire survey with a total of 247 travellers. According to the themes, the survey can be divided into three parts: tourist shopping attitude in Wuzhen, tourist perception of packaging characteristics and their perceived importance of sustainable packaging.

More than ten semi-structures interviews were conducted with selected participant, each lasting approximately 30 minutes. The purpose of the interviews was to explore in depth visitors' experiences and perceptions of packaging in general, as well as in sustainable perspective.

In accordance with the questionnaire completed by Lindh, Olsson and Williams (Helena et al. 2015), Combining the actual situation, the team modified to develop a questionnaire below. The first section of the questionnaire is about personal information, including questions on gender, age, educational background. The section two (table 2) deals with tourists' shopping attitude, perceptions of packaging characteristics and their views on packaging sustainability.

The study measures tourists' attitude towards shopping products in Wuzhen in the form of asking visitors several open-ended questions that provide more information of different views and thoughts expressed in their own words. People's subjective perception of sustainability can be objectively measured by using closed questions, especially the different degrees and differences of views and concepts.

Table 2. The section two of the questionnaire made up of three themes

\begin{tabular}{|c|c|c|}
\hline Theme & Question & Response format \\
\hline \multicolumn{3}{|c|}{ Tourist attitude towards shopping products in Wuzhen } \\
\hline & $\begin{array}{l}\text { Q1 What do you think is the most important activity to } \\
\text { travel in Wuzhen? }\end{array}$ & Free text \\
\hline & $\begin{array}{l}\text { Q2 Would you purchase local products as souvenirs or } \\
\text { gifts before you leave? }\end{array}$ & Yes or no \\
\hline & $\begin{array}{l}\text { Q3 If the Q2 is answered yes, what would you like to } \\
\text { purchase? }\end{array}$ & Free text \\
\hline \multicolumn{3}{|c|}{ Tourist perceptions of packaging characteristics } \\
\hline & $\begin{array}{l}\text { Q4 What do you think is the most important function of } \\
\text { packaging for the goods you purchase? Why? }\end{array}$ & Free text \\
\hline & $\begin{array}{l}\text { Q5 What do you think is the most important aspect of } \\
\text { packaging design for the goods you purchase? Why? }\end{array}$ & Free text \\
\hline & $\begin{array}{l}\text { Q6 What do you think is the most important aspect of } \\
\text { packaging material for the goods you purchase? Why? }\end{array}$ & Free text \\
\hline
\end{tabular}




\begin{tabular}{|l|l|c|}
\hline \multicolumn{2}{|l|}{$\begin{array}{l}\text { Tourist perceived importance of environmentally sustainable } \\
\text { packaging }\end{array}$} & \\
\hline & $\begin{array}{l}\text { Q7 How important do you think the environmental } \\
\text { protection of packaging? }\end{array}$ & Likert five scale \\
\hline & $\begin{array}{l}\text { Q8 How important do you think the environmental } \\
\text { protection of ready-made food packaging is? }\end{array}$ & Likert five scale \\
\hline $\begin{array}{l}\text { Q9 If a product costs 20 RMB, how much are you } \\
\text { willing to pay for environmental package? }\end{array}$ & Single-choice \\
\hline
\end{tabular}

\section{FINDINGS}

According to the table 3, the proportion of men and women participating in the survey is relatively balanced, accounting for $44.53 \%$ and $55.46 \%$ respectively. Most subjects are young and middle-aged, with people aged 31-40 making up the largest group. Over $76.91 \%$ of the participants hold at least bachelor's degree, which means tourists involved in the study have relatively good educational background.

Table 3. Profile of the sample

\begin{tabular}{|l|c|c|r|}
\hline \multirow{3}{*}{ Gender } & Classification & Number & Percentage \\
\cline { 2 - 4 } & Male & 110 & $44.53 \%$ \\
\hline \multirow{3}{*}{ Education } & Female & 137 & $55.46 \%$ \\
\cline { 2 - 4 } & Senior high school and below & 57 & $23.07 \%$ \\
\cline { 2 - 4 } & Undergraduate & 152 & $61.53 \%$ \\
\hline \multirow{3}{*}{ Age } & Master or above & 38 & $15.38 \%$ \\
\cline { 2 - 4 } & $18-25$ & 54 & $21.86 \%$ \\
\cline { 2 - 4 } & $26-30$ & 37 & $14.97 \%$ \\
\cline { 2 - 4 } & $31-40$ & 66 & $26.72 \%$ \\
\cline { 2 - 4 } & $41-50$ & 54 & $14.57 \%$ \\
\cline { 2 - 4 } & $>50$ & 56 & $21.86 \%$ \\
\hline
\end{tabular}

\subsubsection{Function of packaging}

For approximately half of the respondents, the most important for the product packaging in Wuzhen is convenient to carry. Weight and size are key factors that people consider when purchase an item. Therefore, blue calico and black brocade, as inherited classics, were mentioned repeatedly. These are unique traditional folk crafts, lightweight and portable. Traditional sweets were mentioned by $29.27 \%$ of the respondents in consideration of inexpensive price and convenience. Apart from that, convenient for storage (31.58\%) and advantageous in protecting commodity (14.17\%) are also valued by people. Shape and structural elements are shown to influence consumer response. They can carry certain symbolic associations that enable consumers to draw inferences about the products. They further influence consumption amount, albeit through more perceptual and visually driven mechanisms (Festila and Chrysochou 2018). However, there are some packaging design with problems such as easy to damage, inconvenient to carry, difficult to tear or difficult to preserve after opening. Poor packaging design can damage the travel experience of tourists and affect the brand image of tourist destination. In an interview, a couple of participants said that they had the experience of being scratched by packaging box. The inherent complexity of the problem probably give rise to the unsatisfactory structure.

Different packaging shape will also affect food storage efficiency, for example, homemade yoghurt needs to be stored in the freezer for sale, but the capacity and maintenance cost of the freezer are higher than those of ordinary shelves. That requires designers to learn the physical and chemical properties of packaging materials, as well as the mechanical processing and printing properties of packaging materials. Packaging structure design also needs to consider how to protect the product in the process of logistics transportation, so that it has the characteristics of shockproof, moisture-proof, waterproof, mildew proof and rust proof. In the packaging of local products, the harmonious proportion of the parts in contact with the whole packaging shape should be considered in the process of using, so as to bring a comfortable and relaxed feeling to customers. At the same time, the principle of ecological beauty is emphasized to make the whole shape more harmonious and beautiful(Wen-jing 2020). 


\subsubsection{Packaging design}

In addition to sightseeing, tasting delicious food, enjoying local activities and entertainment, shopping is also an activity that more than one third of tourists surveyed will consider when they travel in Wuzhen. As the question "Would you purchase local products as souvenirs or gifts before you leave?", $82.59 \%$ of the people expressed a positive attitude.

When it comes to souvenirs of tourist destination, the general view is that the commodities should have collection properties or excellent packaging worthy of special gifts. When consumers have a wide range of options in terms of value propositions, only products that can distinguish themselves from average commodities are able to capture the benefits of aesthetics and design (Chitturi et al. 2019). Package must draw attention and attract individuals to purchase. This can be achieved through effective choice of colour, pattern, text, texture, logo, and other features.

The research shows that $37.65 \%$ of the consumers in Wuzhen prefer simplicity to luxury so that can avoid unnecessary cost and waste. Innovative designs, in some cases, can lead to rejection (Person et al. 2008); (Celhay and Trinquecoste 2015)). Whereas 26.32\% of the respondents mentioned that the products in tourist attractions should be featured and fashionable, with distinctive element of the ancient town. Sustainable products with aesthetic design are especially important for firms to promoting (Luchs et al. 2012).

$20.24 \%$ of people believe that as gifts for relatives and friends, the packaging should be exquisite and classy. $15.79 \%$ of the respondents surveyed pay attention to packaging information and referred to graphics and words displayed on surface of wrapper. Packaging information should be designed clear, such as shelf life date, manufacturer, ingredients. Some mentioned that food information should provide a clear caloric value reference. Indirect communication, such as colour, can convey attributes like gender and age range in certain situations, that means every element should communicate something. Likewise, graphic elements of packaging design also implicitly communicate sustainability(Steenis et al. 2016). Sometimes, it would be designed to deliberately enlarge.

The sustainable concept emphasizes the strict control of the input cost to ensure the rationality of the packaging cost and the good economy of the product packaging design, which requires design must transmit accurate commodity information and enterprise image, so that the products can achieve the reasonable unity of environmental protection and visual impact. Therefore, design follows the principle of packaging not causing environmental pollution as much as possible in the whole life cycle.

\subsubsection{Packaging material}

Material is the physical carrier for products and the base point for design. The sustainability of design has become a prerequisite for sustainable development. The selection of sustainable materials should meet the requirements of "harmlessness" to ensure that the packaging will not produce harmful substances at different temperatures. The result shows that more than $88.26 \%$ of the visitor was influenced by the environmentally friendly design when they purchase an item, though $11.74 \%$ of the tourists holding the opposite view. When buying ready-made food, most consumers pay attention to whether the product packaging is green and regard it as important, for they believe that would threaten their health. There are merely $2.02 \%$ of the people who don't care about packaging material when they buy ready-made food with high temperature.

The research discovered some shops in Wuzhen used native raw materials as package, just as China's ancient people learned to use natural materials such as leaves, shells, straw, rattan, straw, cloth, linen, shell to wrap foodstuff. They realize the concept of sustainability through redesigning original and non-pollution things. 

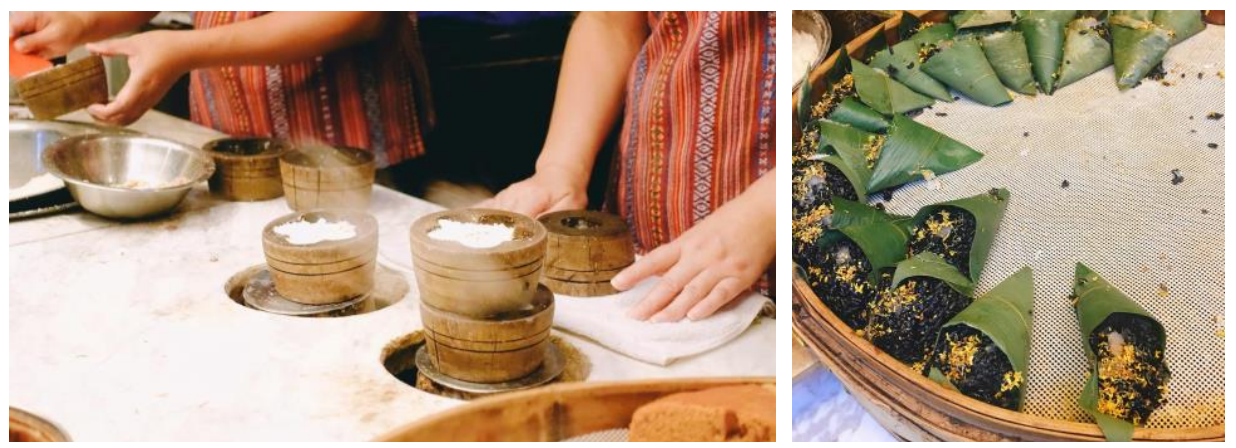

Figure 2. Dingsheng cakes in wooden bowls leaves

As shown in Figure 2, a wooden bowl is used to hold Dingsheng cake. Through high-temperature cooking, the food emits a natural fragrance. Figure 3 shows a pyramid-shaped rice ball wrapped in bamboo leaves. The whole appearance is simple and unique, giving people walking by a visual impression of health and delicious, which also brings good spiritual enjoyment to people tasting it. Food packaging has proven not only to be important to consumers but also to have a great potential to actually contribute to environmental sustainability (Helena et al. 2015).

When it comes to sustainable material, paper is the most frequently mentioned. Glass and metal packaging are considered safe and harmless in most cases. It is found through observation that glass, wood and metal are widely used for packaging in Wuzhen while the most common are paper and plastic. Some businesses even use plastic to hold high-temperature soup and fried food. Because polypropylene (pp) is one of the lightest varieties of plastics, its chemical properties are stable, and non-toxic, tasteless, easy to process, so it is widely used. If the plastic material is buried underground, it will take hundreds of years to decompose. The problem of garbage disposal has become an increasingly important problem in China. Non-degradable plastic cause garbage difficult to deal with. In addition, in order to reduce the cost and improve the physical properties of PP plastics, fillers are usually added. If consumers use PP food with industrial calcium carbonate as filler for a long time, they will have the risk of suffering from gallstones or kidney stones. A large number of heavy metals such as lead and arsenic in the recycled materials will also have chronic harm to the digestive system and nervous system of the human body.

One of the sellers interviewed highlighted the potential additional costs and difficulties of achieving sustainable designs. That could give rise to a commercial disadvantage once they were undercut by competitors or if consumers refuse to buy for the new design concept. The seller also indicated though consumers encouraged more sustainable packaging design, neither customers nor retailers wanted to pay extra for sustainability.

However, the survey showed that the majority of the participants $(94.74 \%)$ are willing to pay an extra for environmentally friendly material, if a package is marked with "environmental protection". Even $9.72 \%$ of the consumers in the study are willing to pay more the $20 \%$ of the total price for sustainable packaging. This indicates that most Chinese consumers are very concerned about the environmental impact of packaging and have a willingness to pay for it.

\section{CONCLUSIONS}

Based on the concept of sustainable development, this paper takes Wuzhen as a case. It analysed visitors' shopping attitude in the tourist destination, $82.59 \%$ of the people surveyed having a strong desire for purchasing souvenirs.

A number of considerations affect consumer acceptance. Considering the problem of carrying on the way home, the commodities with the characteristic of lightness, thinness, shortness are popular with the tourists. Convenient for storage $(31.58 \%)$ and having advantageous in protecting commodity $(14.17 \%)$ are also valued. Design may play an important role in the effectiveness and efficiency of a reusable packaging system, including factors such as (re-) sealability, user-friendliness of (refill) systems, choice of material (e.g. potential for uptake of aromatics in plastic), standardization and pooling, and reduction of product damage and losses (Pmc et al. 2020). In terms of the packaging design style, the research shows that $37.65 \%$ of the consumers in Wuzhen prefer simplicity to luxury, which means beautifully excessive package are not always customers' first choice. The Chinese 
consumers' environmental concerns about packaging is strong. The majority care about what materials are used to wrap food and have a willingness to pay an extra for environmentally sustainable packaging. That presents an opportunity for the packaging industry to advance eco-friendly wrapper. The study applies sustainable concept to product packaging in a tourist destination and provides insights to the packaging industry to further enhance the effectiveness of environmentally sustainable packaging.

\section{REFERENCES}

Bamberg, S. (2003) 'How does environmental concern influence specific environmentally related behaviors? A new answer to an old question', Journal of Environmental Psychology, 23(1), 21-32. https://doi.org/10.1016/S0272-4944(02)00078-6

Beitzen-Heineke, E.F., Balta-Ozkan, N. and Reefke, H. (2017) 'The prospects of zero-packaging grocery stores to improve the social and environmental impacts of the food supply chain', Journal of Cleaner Production, 140(pt.3), 1528-1541. https://doi.org/10.1016/j.jclepro.2016.09.227

Celhay, F. and Trinquecoste, J.F. (2015) 'Package Graphic Design: Investigating the Variables that Moderate Consumer Response to Atypical Designs', Journal of Product Innovation Management, 32(6), 1014-1032. https://doi.org/10.1111/jpim.12212

Chitturi, R., Londono, J.C. and Amezquita, C.A. (2019) 'The Influence of Color and Shape of Package Design on Consumer Preference: The Case of Orange Juice', International Journal of Innovation and Economic Development, 5. http://dx.doi.org/10.18775/ijied.1849-7551-7020.2015.52.2003

Festila, A. and Chrysochou, P. (2018) 'Implicit communication of food product healthfulness through package design: A content analysis', Journal of Consumer Behaviour, 17(5), 461-476. https://doi.org/10.1002/cb.1732

Hao, Y., Liu, H., Chen, H., Sha, Y., Ji, H. and Fan, J. (2019) 'What affect consumers' willingness to pay for green packaging? Evidence from China', Resources Conservation \& Recycling, 141, 21-29. https://doi.org/10.1016/j.resconrec.2018.10.001

Helena, Lindh, Annika, Olsson, Helen and Williams (2015) 'Consumer Perceptions of Food Packaging: Contributing to or Counteracting Environmentally Sustainable Development?', Packaging Technology and Science, 29(1). https://doi.org/10.1002/pts.2184

Huabo, Duan, Guanghan, Song, Shen, Qu, Xiaobin, Dong and Ming (2019) 'Post-consumer packaging waste from express delivery in China', Resources, Conservation and Recycling. https://doi.org/10.1016/j.jclepro.2017.06.036

JoAndrea, Hoegg, Joseph, W. and Alba (2011) 'Seeing Is Believing (Too Much): The Influence of Product Form on Perceptions of Functional Performance’, Journal of Product Innovation Management, 28(3), 346-359. https://doi.org/10.1111/j.1540-5885.2011.00802.x

Kim, N.K. (2008) 'New model of component-based product-oriented environmental management system (CPOEMS) for small and medium-sized enterprises', Brunel University. http://bura.brunel.ac.uk/handle/2438/3492

Koenig-Lewis, N., Palmer, A., Dermody, J. and Urbye, A. (2014) 'Consumers' evaluations of ecological packaging - Rational and emotional approaches’, Journal of Environmental Psychology, 37(mar.), 94-105. https://doi.org/10.1016/j.jenvp.2013.11.009

Licciardello, F. (2017) 'Packaging, blessing in disguise. Review on its diverse contribution to food sustainability', Trends In Food Science And Technology, 65(1), 32-39. https://doi.org/10.1016/j.tifs.2017.05.003

Liu, G., Agostinho, F., Duan, H., Song, G. and Lega, M. (2020) 'Environmental impacts characterization of packaging waste generated by urban food delivery services. A big-data analysis in Jing-Jin-Ji region (China)', Waste Management, 117, 157-169. https://doi.org/10.1016/j.wasman.2020.07.028

Luchs, M.G., Brower, J. and Chitturi, R. (2012) 'Product Choice and the Importance of Aesthetic Design Given the Emotion-laden Trade-off between Sustainability and Functional Performance', Journal of Product Innovation Management, 29(6), p.903-916. https://doi.org/10.1111/j.1540-5885.2012.00970.x

Ma, X. and Moultrie, J. (2017) 'What Stops Designers from Designing Sustainable Packaging? — A Review of Eco-design Tools with Regard to Packaging Design', Springer, Cham. https://doi.org/10.1007/978-3-31957078-5_13

Magnier, L. and Crie, D. (2015) ‘Communicating packaging eco-friendliness', International Journal of Retail \& Distribution Management, 43(4-5), 350-366. https://doi.org/10.1016/j.jenvp.2015.09.005 https://doi.org/10.1108/IJRDM-04-2014-0048

Nordin, N. and Selke, S. (2010) 'Social aspect of sustainable packaging', Packaging Technology and Science, 23(6), 317-326. https://doi.org/10.1002/pts.899

Özgen, C. (2017) 'Sustainable Design Approaches on Packaging Design', Springer, Cham. https://doi.org/10.1007/978-3-319-64349-6_16 
Papanek, V.J. (1971) 'Design for the Real World', Notes from A Seminar, 43--53.

Person, O., Schoormans, J., Snelders, D. and Karjalainen, T.M. (2008) 'Should new products look similar or different? The influence of the market environment on strategic product styling', Design Studies, 29(1), 3048. https://https://dx.doi.org/10.1016/j.destud.2007.06.005 30

Pmc, A., Bc, A., Rtk, B. and Ew, A. (2020) 'Sustainability of reusable packaging-Current situation and trends', Resources, Conservation \& Recycling: X, 6. https://doi.org/10.1016/j.rcrx.2020.100037

Song, G., Zhang, H., Duan, H. and Xu, M. (2018) 'Packaging waste from food delivery in China's mega cities', Resources, Conservation and Recycling, 130, 226-227. https://doi.org/10.1016/j.resconrec.2017.12.007

Steenis, N.D., Herpen, E.V., Van, D., Ligthart, T.N. and Trijp, H.V. (2016) 'Consumer response to packaging design: The role of packaging materials and graphics in sustainability perceptions and product evaluations', Journal of Cleaner Production, S0959652617312052. https://doi.org/10.1016/j.jclepro.2017.06.036

Thanki, S.J. and Thakkar, J.J. (2016) 'Value-value load diagram: a graphical tool for lean-green performance assessment', Production Planning \& Control, 1280-1297. https://doi.org/10.1080/09537287.2016.1220647

Wen-jing, L. (2020) 'Environmental Protection Concept of Food Packaging Design', Packaging Engineering, 41(16), 294-297. https://dx.doi.org/10.19554/j.cnki.1001-3563.2020.16.045

Zhou, M.H., Shen, S.L., Xu, Y.S. and Zhou, A.N. (2019) 'New Policy and Implementation of Municipal Solid Waste Classification in Shanghai, China', International Journal of Environmental Research and Public Health, 16(17). https://doi.org/10.3390/ijerph16173099 


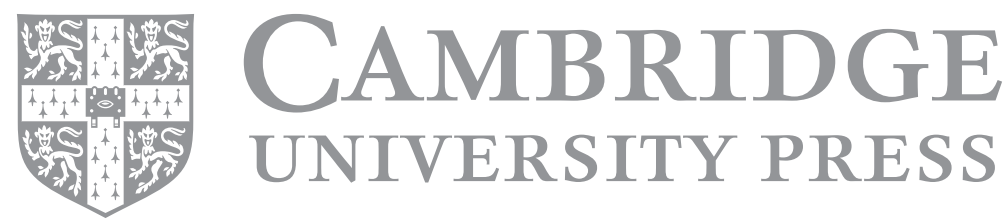

